\title{
Mastopexy in GII Ptosis: Evaluation of Owl Technique Combined with Inferiorly Based Flap
}

\author{
DINA BADAWI, M.D., M.R.C.S.; GAMALAT AZMY, M.Sc. and MOHAMED ASHRAF ELMELEIGY, M.D. \\ The Department of Plastic Surgery, Faculty of Medicine, Cairo University, Egypt
}

\begin{abstract}
Introduction: Mastopexy of small ptotic breasts presents one of the greatest challenges to the plastic surgeons. Different techniques were described for mastopexy as well as for mammary augmentation, recently combining the two procedures became achievable. This may be achieved through inserting an implant, fat lipofilling, or autoaugmantation. Different methods for autoaugmentation mastopexy were mentioned in the literature using the excessive tissue present in one part of the breast to fill the defective parts, mainly the upper pole and the medial cleavage.
\end{abstract}

Objectives: The aim of this study is to evaluate the effectiveness of inferiorly-based pedicle flap, combined with Owl incision, in autoaugmentation mastopexy for patients with small to moderately sized ptotic breasts who desire repositioning of their breasts without insertion of a breast implant nor lipofilling.

Methods: Objective and subjective assessment of 23 female patients undergoing mastopexy with autoaugmantation using the Owl pattern incision combined with the inferior dermoglandular flap.

Results: The technique showed satisfactory results as demonstrates by statistical analysis of the objective and subjective results.

Conclusion: While the autoaugmentation technique could allow the plastic surgeon to partially win the struggle with gravity, the inferiorly-based parenchymal flap that is fixed to the pectoralis major muscle improves the breast projection and upper pole cleavage. It represents a lightweight flap with good outcomes in the long-term follow-up. A circumvertical scar is well appreciated by the patients although has a high learning curve. Adding solid objective assessment tools (anthropometric measures taken before the surgery and at regular follow-up) to the subjective tools (patient's satisfaction) endorses the results and gives data for different statistics.

Key Words: Mastopexy - Ptosis - Owl technique - Inferiorly based flap.

\section{INTRODUCTION}

Aesthetic breast surgery became mandatory procedure almost all-over the world. One of the highly demanded procedures is augmentation mastopexy. Mastopexy of small ptotic breasts presents one of the greatest challenges to the plastic surgeons. The aesthetic goals are to obtain a more youthful appearance, reduced ptosis, and improved projection [1].

The pathophysiology of breast ptosis relates to elongation of the connective tissue reticular network by either stretching, atrophy, loss of elasticity or fibrolipomatous changes. All may lead to increasingly pendulous ptotic breasts with further loss of firmness, projection, and downward pointing nipples. Also, females with a small tuberous breast deformity or patients undergoing unilateral mastectomy with contra-lateral ptotic breast all are seeking mastopexy with or without augmentation [2].

Different techniques were described for mastopexy as well as for mammary augmentation. Recently combining the two procedures became achievable in which implant was used with breast lift in hypoplastic and ptosed breasts. Owing to the higher cost, being unnatural material, and several complications ranging from capsular contractures, bleeding, ruptures, wrinkling, infection, mammographic shadows, capsular calcifications, and bad positioning, so there was a shift to the auto augmentation mastopexy using autologous tissue [3]. When using implants in one-stage augmentation/mastopexy, Castello et al., highlighted the fact that "criticism is logical" as the two procedures have opposing vectors: Filling and stretching the breast with the implant versus removing excess skin and tightening the breast [4].

Different methods for autoaugmentation mastopexy mentioned in the literature used the breast tissue that is mobilized as flap to fill the defective parts. Extended superomedial pedicle was used and rotated to fill the defects in many situations by Alberto et al. [3]. Also, turnover lateral intercostal artery perforator (LICAP) flap secured with a 
pectoralis muscle sling, along with mastopexy for post bariatric ptosed empty breasts was mentioned [5].

Ribeiro described the deepithelialized inferior dermo-lipo-glandular pedicle flap as a robust pedicled flap that may be mobilized to increase the upper pole fullness and projection [6,7]. The same flap was used by Loustau [8] and inserted beneath the parenchyma of a superior based nipple-areolar complex (NAC) bearing flap. Noemi Kelemen et al., used the same flaps with some additions by "stacking" the superomedially based NAC pedicle and medial/lateral glandular pillars on top of the inferiorly based dermoglandular flap [9]. Franz Honig used the same flap to enhance the desired fullness in the upper pole of the breast after removal of breast implant and to avoid insertion of another implant [10].

The inferior dermoglandular flap also provides good vascularization of the lower portion of the breast. This is because the inferior-based flap originates from a dermolipoglandular pedicle that is based on the fourth, fifth, and sixth intercostal perforating vessels of the internal mammary vessel. Even the dermis of the flap can be divided, as long as the inferior portion of the transversely oriented septum of the breast is not violated, because the perforators are located along the septum [10]. In addition, the inferior pedicle allows elevation of the IMF and reduction of the base for optimum aesthetic results [11].

In 2002, Ramirez described the owl technique, which combines the periareolar features in the "round block" technique of Benelli and the vertical reduction of Lassus and Lejour. The shorter scars are useful as they force the surgeon not to rely on the skin envelope for correction of ptosis. The surgeon must search for other tools, like parenchymal redistribution, to support the elevated breast [12].

The aim of this study is to evaluate the effectiveness of inferiorly-based pedicle flap, combined with Owl incision, in autoaugmentation mastopexy for patients with small to moderately sized ptotic breasts who desire repositioning of their breasts without insertion of a breast implant nor lipofilling.

\section{PATIENTS AND METHODS}

23 female patients randomly selected seeking augmentation mastopexy of moderately ptosed breasts without implant insertion. (Sample size calculation was carried out to determine the appropriate sample size. The alpha value is set at $p<0.05$ and power $(\beta)$ of $90 \%$ is chosen. A paired difference in outcome $(\mathrm{N}-\mathrm{SN})$ is expected to be $33 \% \pm 33 \%$ decrement (from 32 to $21 \mathrm{~cm}$ ). The sample size was 19 participants. However, with a dropout rate of $15 \%$, the required sample size was 23 participants). The study was carried out in Plastic and Reconstructive Surgery Department in Kasr AlAini Hospitals during the period from January 2018 to July 2018.

\section{Inclusion criteria:}

- Moderately ptosed breast (second degree ptosis) according to Regnault [13] classification system.

- Patients wishing augmentation mastopexy without implant insertion nor lipofilling.

\section{Exclusion criteria:}

- Previous breast surgery.

- Lactating females.

- Nipple discharge or bleeding.

- History of breast lumps.

- Uncontrolled diabetes and hypertension.

- Very small atrophied breast.

- Higher grades of ptosis.

- Psychologicall unstable patients.

- Skin problems (pyoderma gangrenosum, intertrigo).

\section{Preoperative assessment:}

- Preoperative laboratory investigations and breast scanning.

- Preoperative marking while the patient in the standing position: Marking the distances between the nipple and the suprasternal notch $(\mathrm{N}-\mathrm{SN})$, between the nipple and the infra-mammary fold (N-IMF), and the inter-mammary distance (IMD) as well as recording the bra cup size.

- The inferior pedicle flap marked: Upper border is $2 \mathrm{~cm}$ below NAC.

\section{Operative technique:}

Under general anesthesia, after deepithelialization of the peri-areoalar and pedicle area, the superior pedicle carrying the NAC is separated from the lower triangular flap (Fig. 1). The superior flap carrying the NAC is undermined till the level of the second $\mathrm{d}$ rib to create a pocket beneath it (Fig. 2). The inferior deepithelialized pedicle is dissected from its medial, lateral margins till the pectoralis fascia. The dermis is completely incised at its lower margin. The flap is not dissected deeply from the pectoralis fascia to preserve the integrity of its blood supply (Fig. 3). 
The inferior flap is folded underneath the superior pedicle carrying the NAC and fixed to the pectoralis major fascia at the level of the second rib with 3-4 polypropylene sutures (Fig.

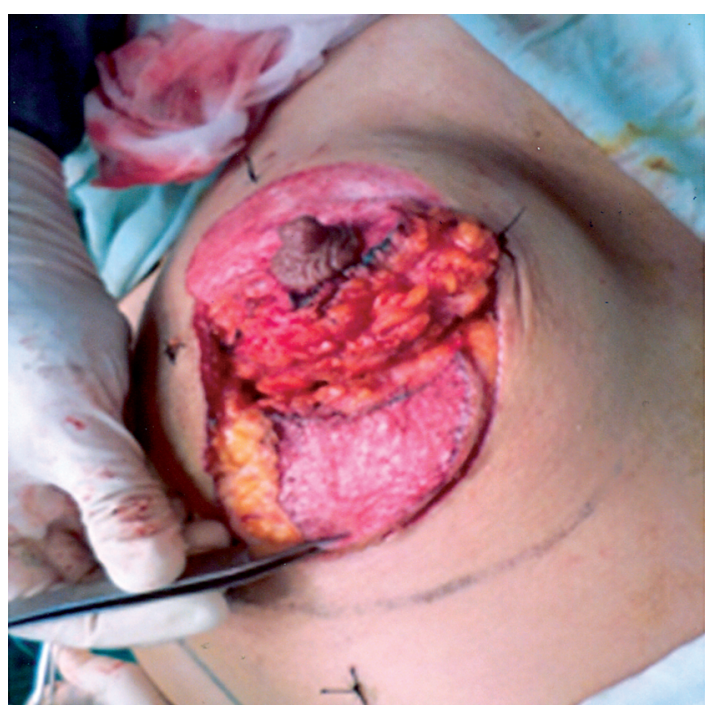

Fig. (1): The superior pedicle carrying the NAC is separated from the lower triangular flap.
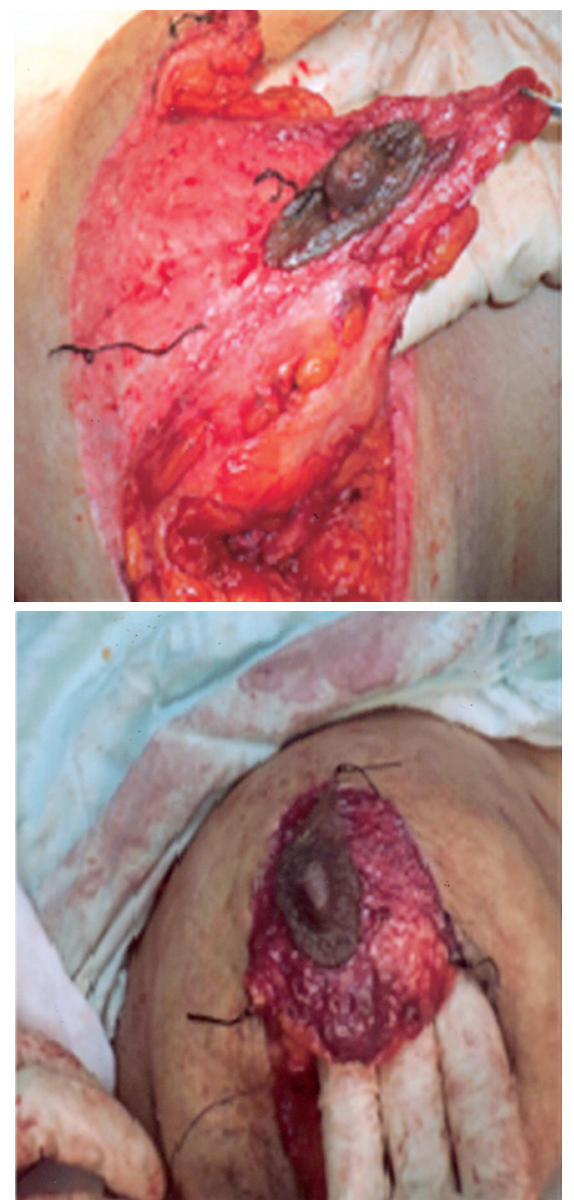

Fig. (2): The superior flap carrying the NAC is undermined till the level of the second $d$ rib to create a pocket beneath it.
4). Closure of the periareloar incision via a round block technique using a purse-string suture and finally, the vertical limb in sutured in layers.

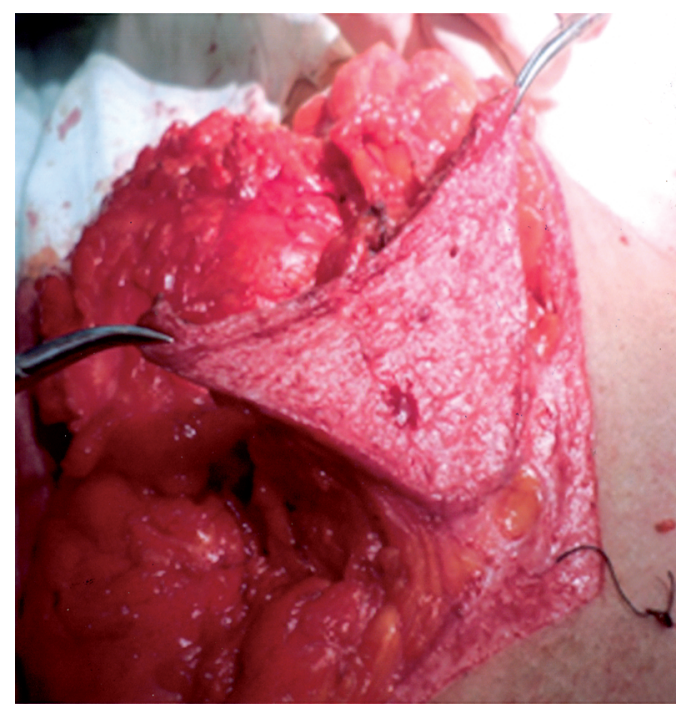

Fig. (3): The inferior deepithelialized pedicle is dissected from its medial, lateral and lower margins. No dissection from the pectoralis fascia to preserve the integrity of its blood supply.
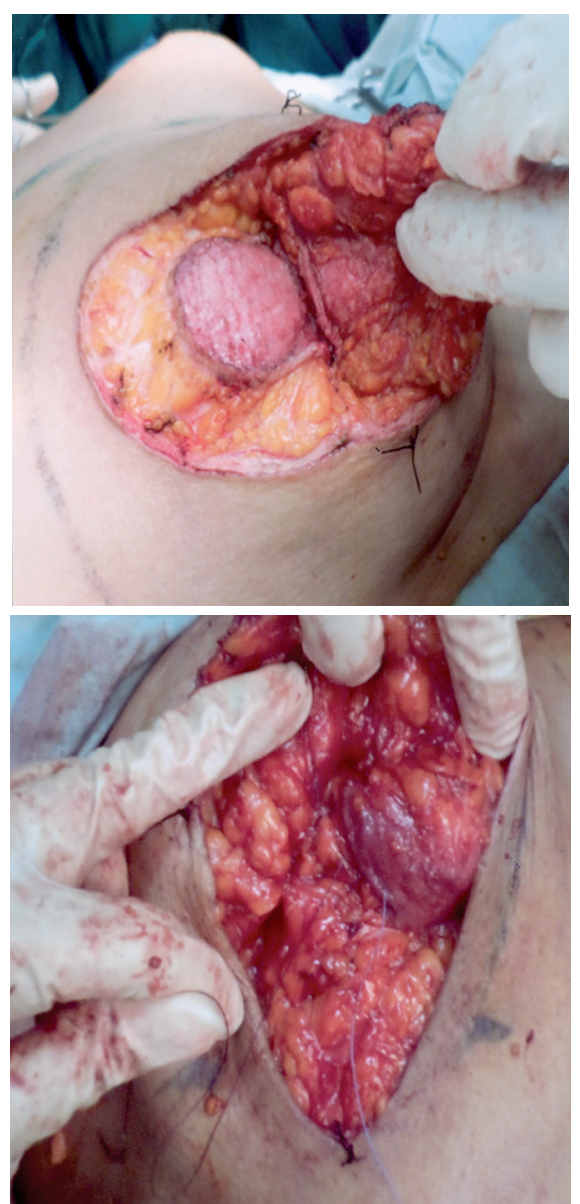

Fig. (4): Inferior flap folded underneath the superior pedicle carrying the NAC and fixed to the pectoralis major fascia at the level of the second rib. 
Post-operative assessment tools:

Follow-up period done at 3,6 and 12 months using:

- Post-operative photos.
- Justifying measurements and parameters: Measurement of (N-SN), (N-IMF), and (IMD).

- Bra cup size.

- Patient satisfaction questionnaire (Table 1).

\begin{tabular}{|c|c|c|c|c|}
\hline Name: & & $\ldots$ & \multicolumn{2}{|l|}{ Age: } \\
\hline Height: & & & \multicolumn{2}{|c|}{ Weight: } \\
\hline \multicolumn{5}{|c|}{ Address: $\cdots$} \\
\hline Marital status & $\square$ Married & & $\square$ Separated & $\square$ Single \\
\hline Menstrual history: & $\square$ Regular & & $\square$ Irregular cycles & $\square$ Post-menopausal \\
\hline \multicolumn{5}{|c|}{ Duration since underwent auto-augmentation mastopexy: } \\
\hline Bra cup size befor & surgery: & 2 & \multicolumn{2}{|c|}{ Bra cup size after surgery: } \\
\hline \multicolumn{5}{|c|}{ Degree of satisfaction regarding breast lift degree: } \\
\hline$\square$ Excellent & $\square$ Very good & $\square$ Good & $\square$ Fair & $\square$ Not satisfied \\
\hline \multicolumn{5}{|c|}{ Degree of satisfaction regarding scar: } \\
\hline$\square$ Excellent & $\square$ Very good & $\square$ Good & $\square$ Fair & $\square$ Not satisfied \\
\hline \multicolumn{5}{|c|}{ Degree of satisfaction regarding breast and nipple areola sensation: } \\
\hline$\square$ Excellent & $\square$ Very good & $\square$ Good & $\square$ Fair & $\square$ Not satisfied \\
\hline \multicolumn{5}{|c|}{ Degree of satisfaction regarding postoperative pain toleration: } \\
\hline$\square$ Excellent & $\square$ Excellent & $\square$ Excellent & $\square$ Excellent & $\square$ Excellent \\
\hline \multicolumn{5}{|c|}{ Degree of satisfaction regarding breast cup size: } \\
\hline$\square$ Excellent & $\square$ Excellent & $\square$ Excellent & $\square$ Excellent & $\square$ Excellent \\
\hline \multicolumn{5}{|c|}{ Degree of satisfaction regarding breast shape: } \\
\hline$\square$ Excellent & $\square$ Excellent & $\square$ Excellent & $\square$ Excellent & $\square$ Excellent \\
\hline \multicolumn{5}{|c|}{ Degree of satisfaction regarding breast projection: } \\
\hline$\square$ Excellent & $\square$ Excellent & $\square$ Excellent & $\square$ Excellent & $\square$ Excellent \\
\hline
\end{tabular}

Table (1): Patient satisfaction questionnaire.

\section{RESULTS}

In the study population (23 cases), the age was between 27-50 years with mean age 36.96 \pm 6.24 SD the BMI was between 23.4-30.8 with mean value $27.46 \pm 5.30 \mathrm{SD}$.

\section{1- Anthropometric measures (Fig. 5):}

There was significant decrease in (N-SN) and (N-IMF) distances. The right breast (N-SN) distance from $31.21 \pm 3.99 \mathrm{SD}$ preoperative to $21.13 \pm 2.07$ SD 3 months postoperative, $22.17 \pm 1.89$ SD 6 months post-operative, and 23.43 $\pm 2.21 \mathrm{SD} 1$-years post-operative with significant $p$-value $<0.0015$. The left breast $(\mathrm{N}-\mathrm{SN})$ distance with mean preoperative of $31.28 \pm 4.33 \mathrm{SD}$, and 3 months postoperative of $21.41 \pm 1.92 \mathrm{SD}$ at 6 months post-operative was 22.28 $\pm 21.12 \mathrm{SD}$ and at 1 year was $23.76 \pm 3.36$ SD with highly significant $p$-value 0.004 . As regard $\mathrm{N}$-IMF the mean preoperative value was $13.04 \pm 1.01$ SD for the right side, became $10.35 \pm 0.88 \mathrm{SD}$ after 3 months and $10.67 \pm 0.87$ SD after 6 months and at 1 year became $11.13 \pm 0.97 \mathrm{SD}$ with significant $p$-value 0.000 and for the left N-IMF the preoper- ative value was $12.98 \pm 1.03 \mathrm{SD}, 10.37 \pm 0.92 \mathrm{SD}$ at 3 months, $10.57 \pm 0.89 \mathrm{SD}$ at 6 months, $10.93 \pm 0.93$ $\mathrm{SD}$ at 1 year with significant $p$-value 0.000 . As regards IMD, it was $21.78 \pm 1.40 \mathrm{SD}$ preoperative, became 19.96 $\pm 1.32 \mathrm{SD}$ at 3 months, $20.48 \pm 1.16$ SD at 6 months, $20.85 \pm 1.22 \mathrm{SD}$ at 1 year with significant $p$-value 0.002 .

\section{2- Bra cup size (Fig. 6):}

As regard change in cup size, 3 cases (13.04\%) showed increase by 2 degrees, and 11 cases (48\%) showed increase by 1 degree.

8 cases $(35 \%)$ showed no considerable change in cup size and 1 case (4.3\%) showed decrease in cup size by 1 degree. As a conclusion, there was a mean increase in cup size $1.65 \pm 1.77$ SD 3, 6 months and 1-year post-operative, with significant $p$-value of 0.001 .

\section{3- Patient satisfaction (Fig. 7):}

$39.2 \%$ (9) of patients claimed to have an excellent breast lift, $34.8 \%$ (8) a very good breast lift, $13 \%$ (3) good lifting and 13\% (3) fair lift, with a 
mean preoperative satisfaction of $1.43 \pm 0.59 \mathrm{SD}$ and postoperative mean satisfaction value of

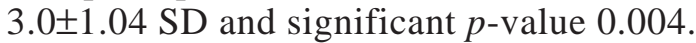

In addition, $43.5 \%$ (10) claimed to have excellent breast size, $34.8 \%$ (8) very good size and $21.7 \%$ (5) good size, with a mean preoperative breast size satisfaction of $2.13 \pm 0.69 \mathrm{SD}$ and a mean post-operative breast size satisfaction of $3.22 \pm 0.80$ SD and significant $p$-value of 0.002 .

As regard breast shape $34.8 \%$ (8) patients claimed to have excellent breast shape, $39.1 \%$ (9) very good breast shape, $17.4 \%$ (4) good breast shape and $8.7 \%$ (2) fair shape, with a mean preoperative satisfaction value of $1.35 \pm 0.57 \mathrm{SD}$, and mean post-operative satisfaction value of $3.0 \pm 0.95$ $\mathrm{SD}$, and $p$-value significance of 0.001 .

As regard breast projection, 34.8\% (8) of study population claimed to have excellent projection,
$34.8 \%$ (8) very good projection, $17.4 \%$ (4) good projection and $13 \%$ (3) fair projection, with a mean preoperative satisfaction value of $1.30 \pm 0.47 \mathrm{SD}$, and a mean post-operative satisfaction value of

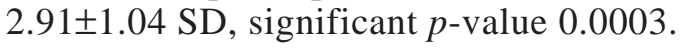

As regard nipple areola sensation, $21.7 \%$ (5) of population claimed to have excellent nipple areola sensation, 39.1\% (9) very good sensation, $26.1 \%$ (6) good sensation, $13 \%$ (3) fair sensation and none of the study population claimed to have lost sensation.

As regard scar shape $26.1 \%$ (6) claimed to have very good scar, $43.5 \%$ (10) good scar, $26.1 \%$ (6) fair scar shape, $4.3 \%$ (1) bad scar.

As regard postoperative pain tolerance $17.4 \%$ (4) had excellent pain tolerance, $43.5 \%$ (10) very good pain tolerance, $21.7 \%$ (5) had good pain tolerance and $17.4 \%$ (4) fair pain tolerance.

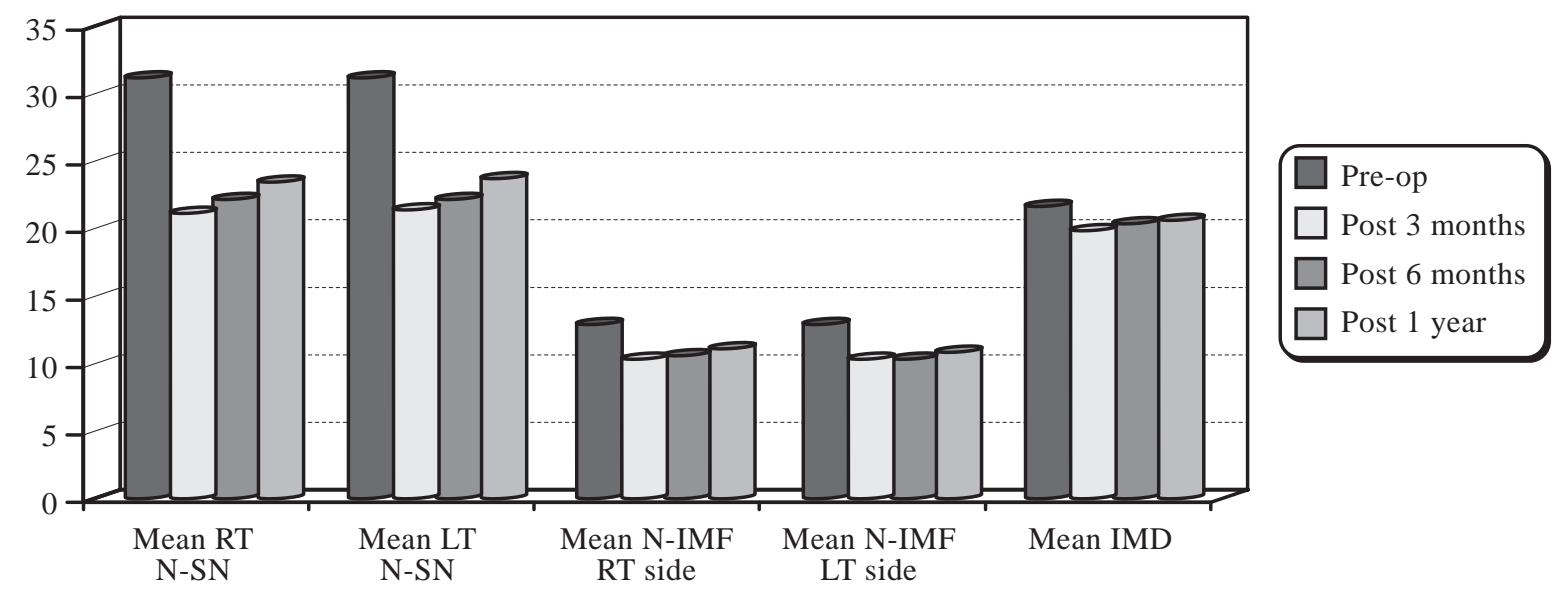

Fig. (5): Comparative values of N-SN, N-IMF, IMD pre-operative and 3, 6 months and 1-year post-operative.
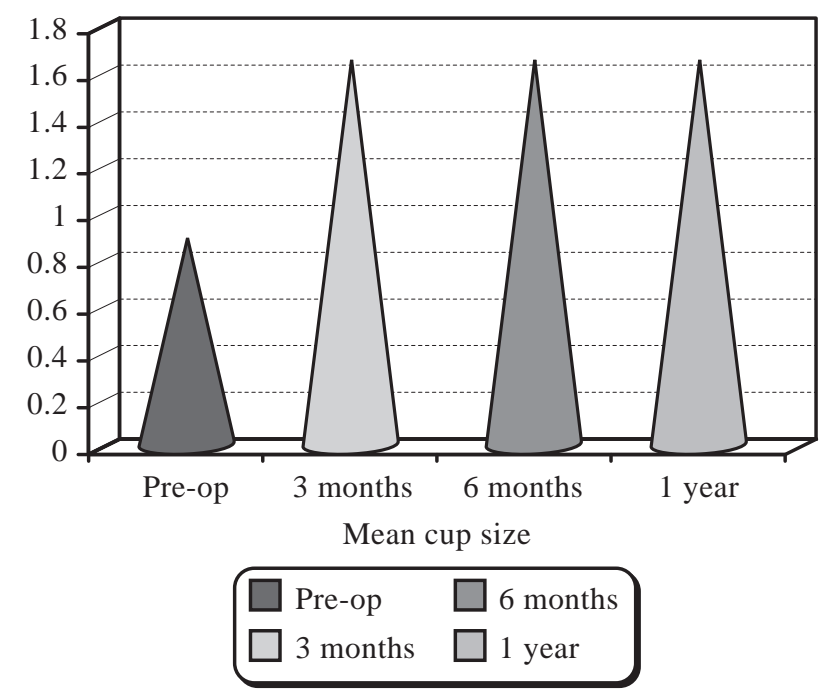

Fig. (6): Change in mean cup size preoperative and 3, 6 months, 1-year post-operative.

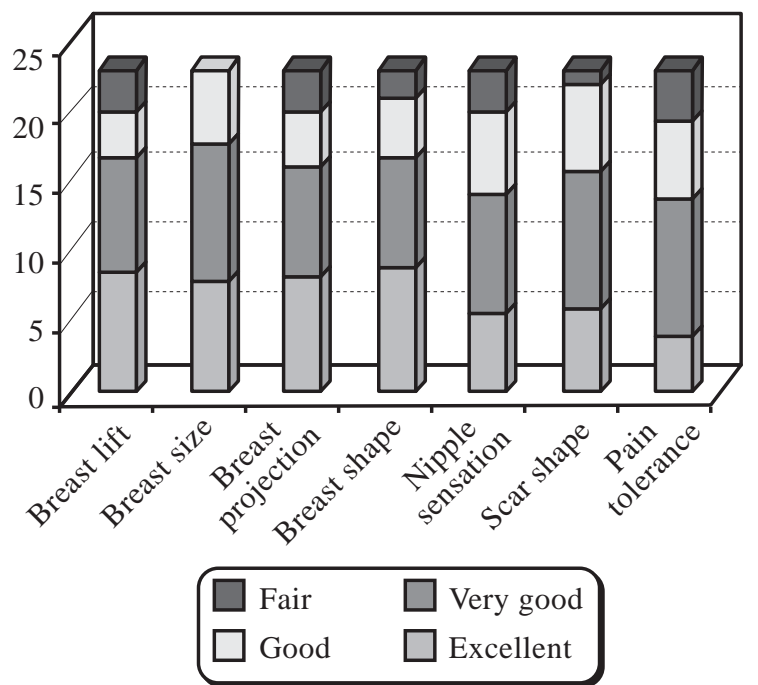

Fig. (7): Incidence of post-operative patient satisfaction after 1 year among study population. 

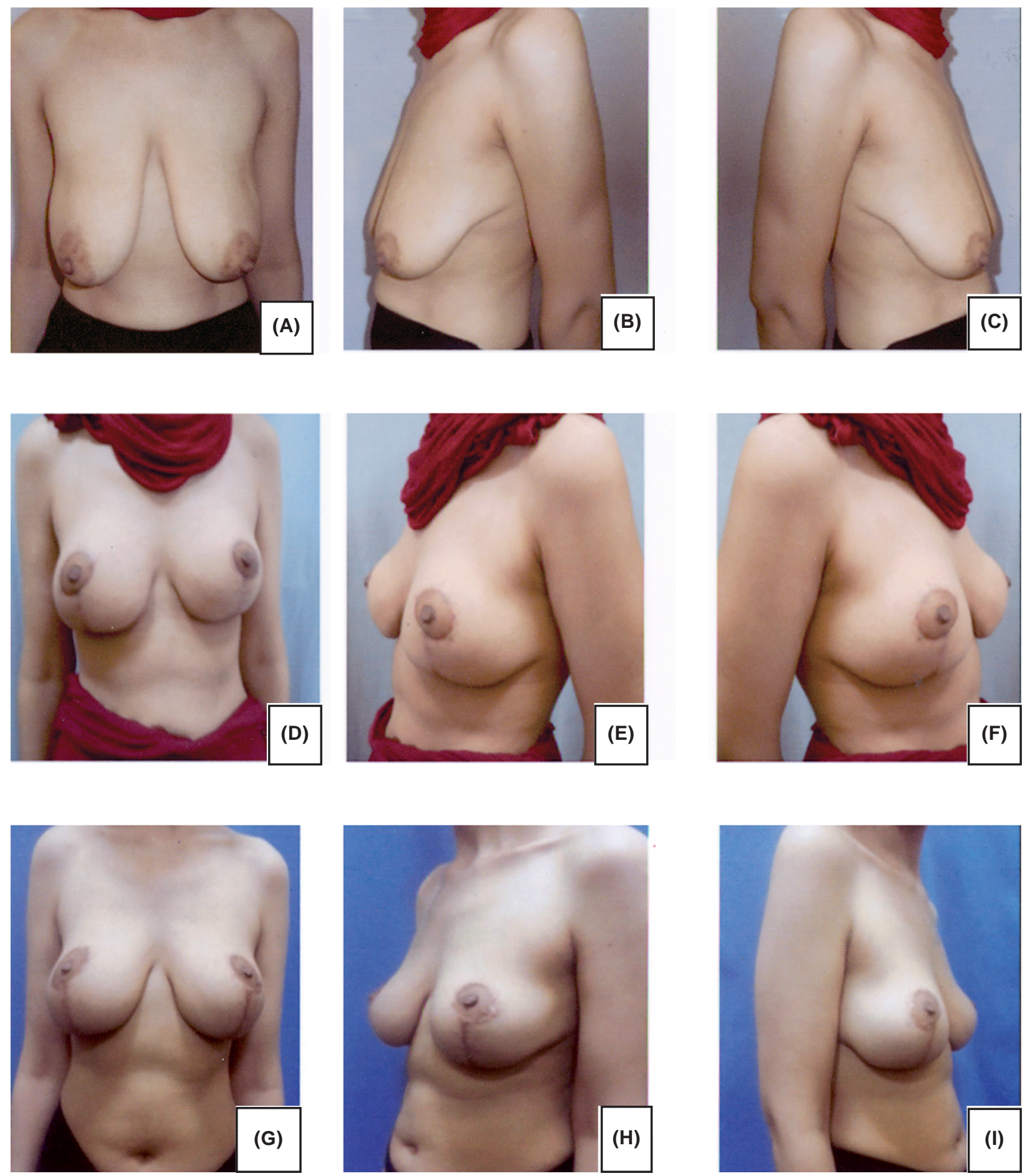

Fig. (8): 32 years old female (A-C): Pre-operative, (D-F): 3 months post-operative, and (G-I): 9 months post operative. 

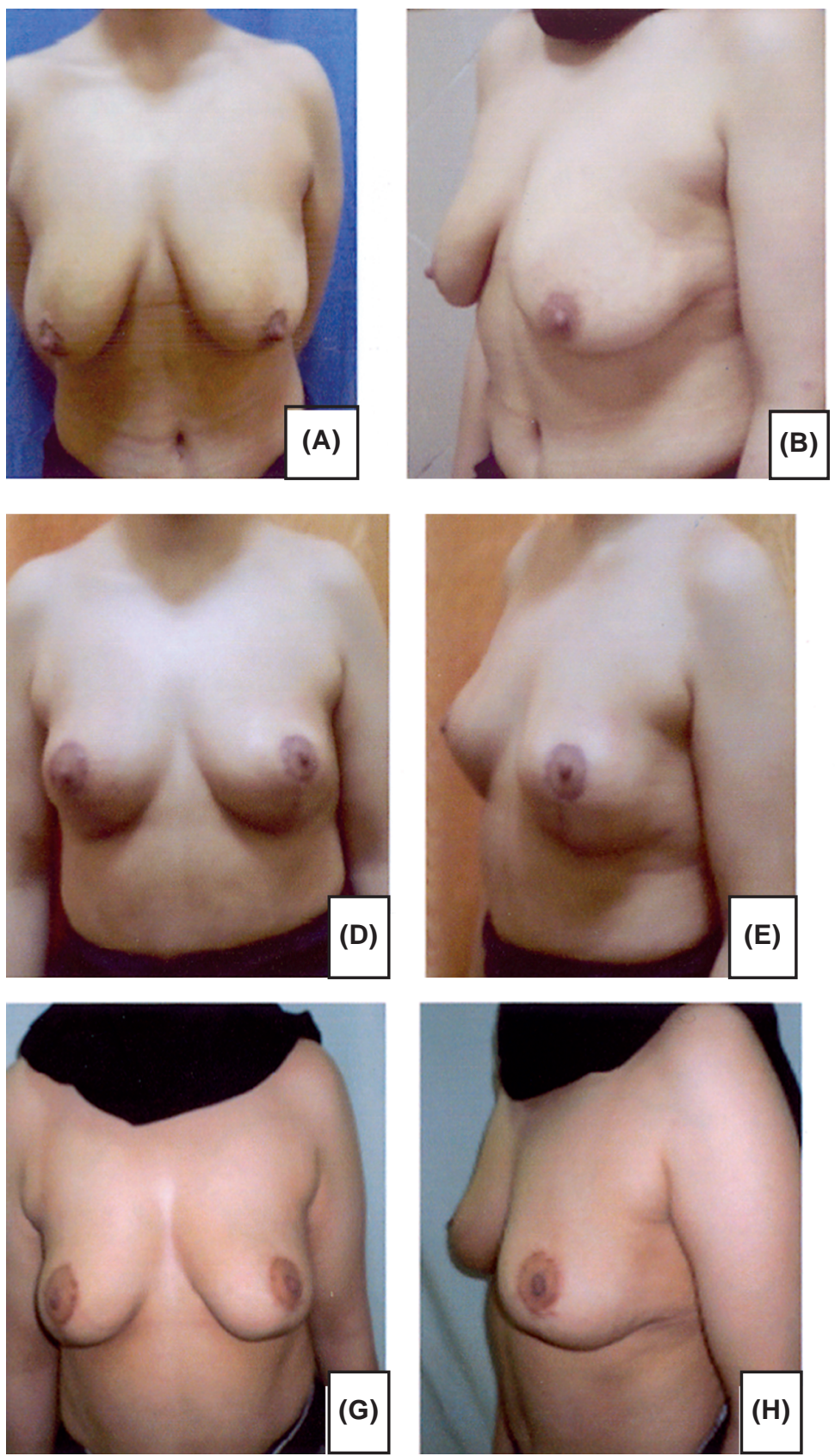
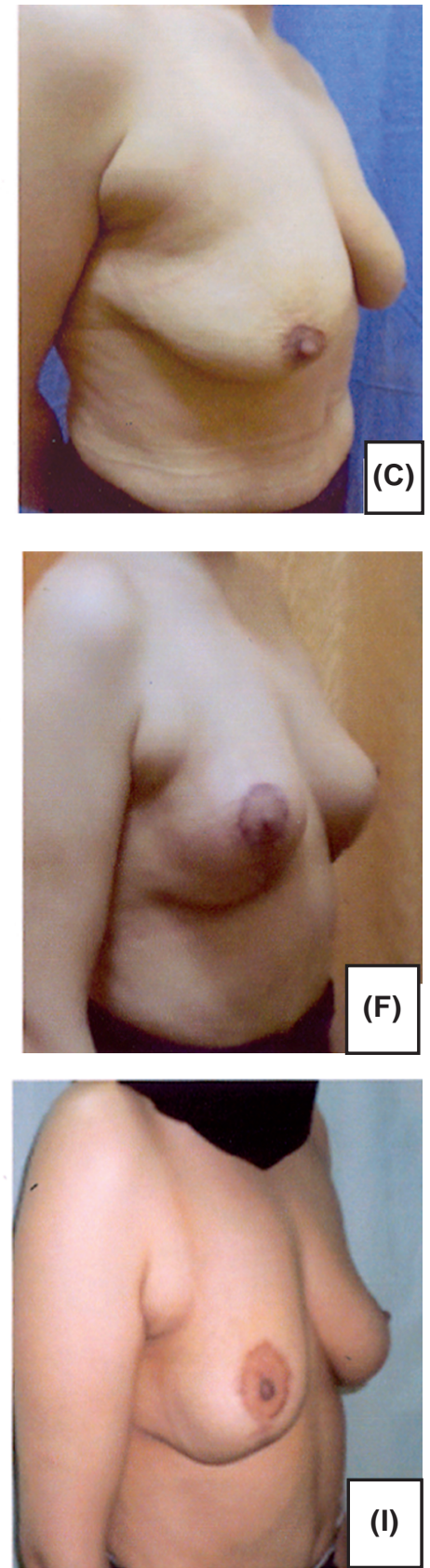

Fig. (9): 43 years old female (A-C): Pre-operative, (D-F): 3 months post-operative, and (G-I): 9 months post operative.

\section{DISCUSSION}

Mastopexy of small and medium-size breasts without a decline in size, while improving their projection, and maximizing the fullness of the upper pole, has always been a great challenge for surgeons. An anatomic-based approach relying on reshaping and tightening the breast parenchyma, supporting the NAC in its new position and proper redraping of the skin envelope must be adopted to optimize the results [14].

The first challenge faced by the surgeon is the desire of the patient to obtain a "fuller" breast while she expresses no desire to use breast implants and at the same time is not candidate for augmentation with autologous fat. Here, as we do not increase the real size of the breast, we have to increase the apparent size and to augment the projection. Different method for autoaugmentation mastopexy were mentioned in the literature using the excessive tissue that may be present in some parts of the breast and redistributing it (ensuring its blood supply is maintained) to achieve an aesthetic looking breast.

In our technique, we recognized the importance of the inferior dermoglandular flap as a tool very 
useful in providing the upper breast cleavage, augmenting the projection and increasing the apparent volume. Compared with the lateral pedicle advocated in some reduction mammaplasty procedures for autoaugmentation, which offers limited recruitment of tissue, the inferior pedicle is designed to give a better breast shape, with upper fullness and more volume [15].

However, mastopexy without any breast parenchyma reduction carries much pressure on the

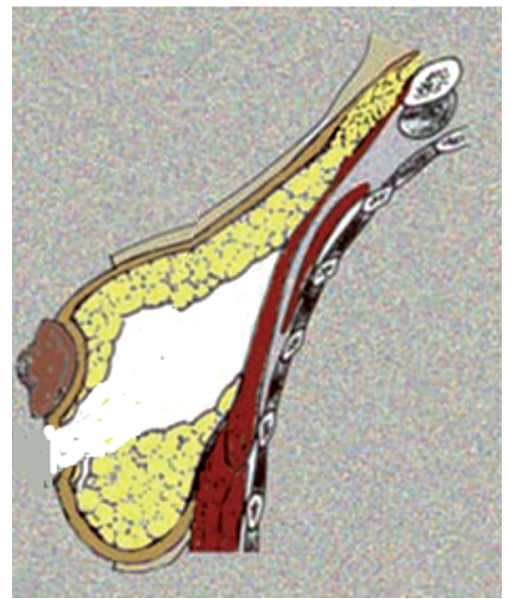

Fig. (10): Dissection of a pocket superiorly makes in-setting of the inferior flap easier and with less tension on the wound.

The second challenge faced by the surgeon is the scar. Here the surgeon is facing two opposing goals: To increase the amount of skin removed to treat the redundancy and tighten the breast, and at the same time to satisfy the patient's desire for a scar as much hidden as possible. Despite the fact that the classic inverted $\mathrm{T}$ pattern is known to have extensive scar length, poor long-term shape, and stretching the already thin skin, still it has its "advocators" among the surgeons. "Cut as you go" skin excision, is an expression used when the lateral and medial extents of the IMF incision are determined intraoperatively and may even exceed the preoperative limits, following the inferior curve of the breast and upward toward the anterior axillary fold. This is claimed to narrow the breast base, making it less boxy [9]. In periareolar techniques, the challenge is to maintain the areolar diameter without long term stretching as the tension on the skin favors scar widening. This is more commonly seen when augmentation is added to mastopexy. On the other hand, when vertical scar component is added, this tension is diminished [8].

In our study, we used the owl technique which combines the features of the vertical reduction and the large periareolar reduction. This allows important skin envelope reduction while maintain the wound closure: The made-smaller skin envelope has to fit around the same original-size parenchyma, without any tension on the wound. We adopted Noemi et al., technique as he dissected underneath the medial and lateral flaps, as well as deep to the superior pedicle to create a pocket. This dissection created a room in the upper and medial breast to incorporate the inferior demoglandular flap with easier redraping of the skin over the new breast (Fig. 10).

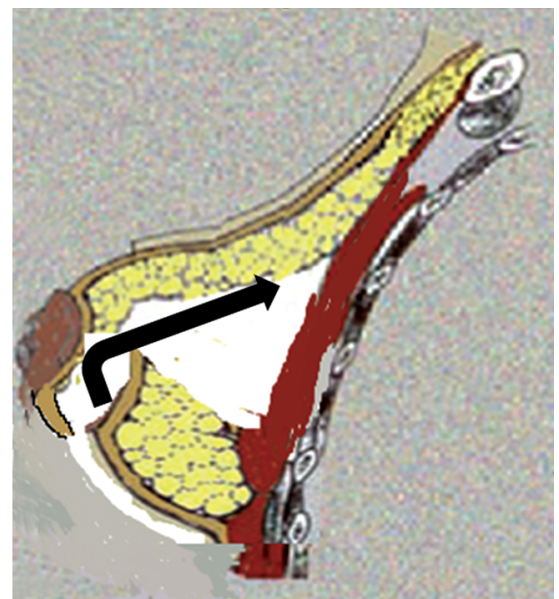

breast projection. We adopted the addition of the purse-string suture in closing the periareolar incision to ensure good-quality scars and avoid areolar enlargement [16]. This scar pattern yielded a high patient satisfaction rate regarding the breast projection, and the scar perception.

The third challenge faced in autoaugmentation mastopexy is providing longevity to the results, with no post-operative bottoming-out or decrease in size (atrophy of the flap). The milestones to obtain long term results are adding as much possible tissue to the inferior dermoglandular flap, ensuring a robust reliable blood supply to the flap and providing good attachment to the flap. When Kim [17] elevated the inferior glandular flap on a superior dermal pedicle blood supply. There was $6.8 \%$ incidence of seroma and fat necrosis of distal flap during follow-up. This denotes affected vascularity due to excessive length of the flap and the fact that the superior-based dermoglandular pedicle was elevated off the pectoralis fascia. In our study, we kept the connection between the pectoralis fascia and the deep surface of the inferior to ensure robust pedicled blood supply to maintain the long-term viability of the flap. We also followed Honïg et al., steps [10] by making the inferior flap $2-4 \mathrm{~cm}$ thick and incorporating in its width all the distance 
between the lateral and medial borders of the breast pillars. This recruited a large portion of dermoglandular tissue from the lower pole to the upper pole of the breast. For fixation of the flap superiorly, we used exclusively the pectoralis muscle fascia. We agree with Honïg that the pectoralis muscle fascia achieves durable autologous breast parenchymal suspension and avoids adding extra tension on the wounds. In our study only 1 patient presented by re-ptosis after 1 year after losing $6 \mathrm{~kg}$ of her weight post-operatively.

\section{Conclusion:}

While the autoaugmentation technique could allow the plastic surgeon to partially win the struggle with gravity, the inferiorly-based parenchymal flap that is fixed to the pectoralis major muscle improves the breast projection and upper pole cleavage. It represents a lightweight flap with good outcomes in the long-term follow-up. A circumvertical scar is well appreciated by the patients although has a high learning curve. Adding solid objective assessment tools (anthropometric measures taken before the surgery and at regular followup) to the subjective tools (patient's satisfaction) endorses the results and gives data for different statistics.

\section{REFERENCES}

1- Ali A.: Mastopexy autoaugmentation: A simple method which keeps the size of the breast and enhances its projection, Egypt, J. Pplast. Reconstr. Surg. July, 34 (2): $197-$ $201,2010$.

2- Spear S.L. and Venturi M.L.: Augmentation with periareolar mastopexy. In S. SL, surgery of the breast: Principles and arts (pp. 1393-1402). Philadelphia: Lippincott Williams \& Wilkins, 2006.

3- Saito A.O.: Mastopexy after massive weight loss: Dermal suspension, parenchymal reshaping, and augmentation with autologous tissue. Rev. Bras. Cir. Plást., 27 (2): 283 9, 2012.

4- Manuel Francisco Castello A.S.: Augmentation mammo- plasty/mastopexy: Lessons learned from 107 aesthetic cases. Aesth. Plast. Surg., 523-26, 2014.

5- Hamdi M., Van Landuyt K., Blondeel P., et al.: Autologous breast augmentation with the lateral intercostal artery perforator flap in massive weight loss patients. Plastic, Reconstructive \& Aesthetic Surgery, 62 (1): 65-70, 2007.

6- Ribeiro L.: A new technique for reduction mammaplasty. Plast. Reconstr. Surg., 55: 330-4, 1975.

7- Ribeiro L., Accorsi A.Jr., Buss A. and Marcal-Pessoa M.: Creation and evolution of 30 years of the inferior pedicle in reduction mammaplasties. Plast. Reconstr. Surg., 110: 960-970, 2002.

8- Hugo D. Loustau, Horacio F. Mayer and Manuel Sarrabayrouse: The owl technique combined with the inferior pedicle in mastopexy. Aesthetic Plast. Surg. Jan., 32 (1): 11-17, 2008.

9- Kelemen N., Kannan R.Y. and Offer G.J.: A stacked technique of mastopexy: Volume redistribution mastopexy with inferior flap and superomedially based pedicle. Aesthetic Plast. Surg. Apr., 37 (2): 349-53, 2013.

10- Johannes Franz Honig, Hans Peter Frey, Frank Michaael Hasse and Hasselberg: Autoaugmentation mastopexy with an inferior-based pedicle. Aesth. Plast. Surg., 34: 447454, 2010.

11- Manish C. Champaneria: The evolution of breast reconstruction: Historical perspective. World Journal of Surgery, 36 (4): 730-742, 2012.

12- Loustau H.D.1, Mayer H.F. and Sarrabayrouse M.: The owl technique combined with the inferior pedicle in mastopexy. Aesthetic Plast. Surg. Jan., 32 (1): 1-5, 2008.

13- Regnault P.: Breast ptosis: Definition and treatment. Clin. Plast. Surg., 34 (2): 193-203, 1976.

14- Abozeid M. and Badawi D.: Augmentation mastopexy: Implementing autologous breast tissue for optimum results; case series study with a nine-month follow-up. Egypt J. Plast. Reconstr. Surg., 43 (1): 31-39, 2019.

15- Hall-Finday E.J.: Pedicles in vertical breast reduction and mastopexy. Clin. Plast. Surg., 29: 379-391, 2002.

16- Rosen A.: Periareolar closure with barbed sutures. Aesth. Surg. J., 36 (3): 372-5, 2016.

17- Kim P., Kim K. and Casas L.: Superior pedicle autoaugmentation mastopexy: A review of 34 consecutive patients. Aesthetic Plast. Surg., 30 (2): 201-210, 2010. 